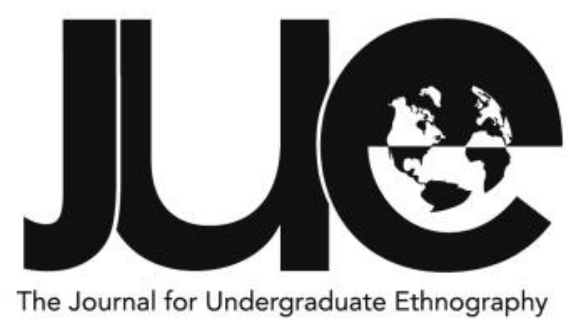

\title{
Blurred Boundaries and Strategic Surveillance: Regulating Behaviour in Bristol's Commercialised Spaces
} Jonathan Fuller

University of Bristol, jf15547@my.bristol.ac.uk

\section{ABSTRACT}

This article explores how models of architecture, surveillance, and ownership define commercialised spaces, and in turn dictate how these spaces are experienced - not only by their users but also by the ethnographer. I argue that the supposedly inclusive and open design of Cabot Circus in the city centre of Bristol, UK, has resulted in a privatised, impersonal and exclusionary shopping centre. Its mode of operation and regulation threatens to encroach on the adjacent publicly accessible commercial area of Broadmead, through events like the Christmas market, which blurs the boundaries between the two environments. By reflecting on the difficulties I faced as an ethnographer when attempting to conform to my expected role in the space as an active and visible participant, I suggest that power has become so deeply embedded in the contemporary shopping centre that an innovative and reflexive methodological approach is necessary to capture the true machinations of the privatisation of urban public space. By directing attention towards recent efforts to privatise law enforcement and regulate visitor behaviour in these reconfigured commercialised spaces, this research also raises more 'fundamental questions about how urban citizenship and social exclusion are defined', simultaneously exposing the 'importance of consumption... to daily urban life' (Flint, 2002: 66).

Keywords: public space, urban regeneration, privatisation, surveillance, consumption 
-his research critically compares two commercialised spaces in Bristol's city centre, namely the privatised Cabot Circus and the publicly accessible Broadmead. Influenced by the writings of Bauman (2000) and Foucault (1995), this article empirically explores the ways in which distinctive architectures operate alongside differing surveillance strategies to facilitate the constant maintenance of two regulated yet visually contrasting shopping environments. By focussing specifically on the dichotomy between the largely discreet surveillance present within Cabot Circus, on the one hand, and the ways in which the social and cultural authenticity of Broadmead becomes increasingly subjected to visible regulation upon the arrival of Bristol's Christmas market, on the other, it is suggested that the boundaries between the two commercialised spaces have become increasingly 'fluid, fought over and negotiated, requiring them to be continually sustained and controlled' (Phillips 2010, 279). This ultimately results in a contemporary city centre shopping district where power and regulation have become deeply embedded within the space itself (Allen 2006, 442), posing challenges for researchers attempting to conduct fieldwork in an environment that is not conducive to the immersive, interactive participation in a social context that ethnography normally involves. Drawing on my field observations, I suggest that a combination of design, location and intended purpose 'contribute to determining whether surveillance works to "open"... or to "close" (Koskela 2000, 261) such commercialised spaces, simultaneously dictating 'our relation to the space, our relationships in the space, and importantly our desire or ability to even use the space' (Levy and Church, 2012: 3).
This article begins with a discussion of the key theoretical debates surrounding the relationship between architectural design and human surveillance methods in the creation and usage of contemporary commercial spaces, highlighting the case study of Bristol's Cabot Circus shopping centre development. The article then turns to consider my methodology, reflecting on the influence that this distinctively impersonal commercialised space had on the observational approach that I adopted. From this, I draw upon visual observations and photographs to outline the key findings of my comparative analysis, beginning with Cabot Circus, before moving onto consider the ways in which the authenticity of Broadmead has been adversely affected by the pursuit of power, privatisation and profit.

\section{Architecture and surveillance}

Much of the sociological literature surrounding the design and usage of shopping centres has applied Foucault's (1995) notion of the panopticon in order to emphasise the relationship between architectural design and human surveillance methods. This relationship is used strategically as a way to encourage selfregulation and 'seduce shoppers into spending money' (Stillerman and Salcedo 2012, 310), thus facilitating the ongoing 'maintenance of normality among the already normal' (Koskela 2000, 253). Here, Allen (2006, 442) has suggested that 'power no longer needs to be confrontational or marked out physically to be effective'. Meanwhile, other scholars have noted that, in order to maximise visitors' consumption, architectural design continues to be widely employed in conjunction with modern surveillance methods, such as CCTV, as a means for enabling the successful 'technologization of space' (Koskela 2000, 251). Moreover, it has more recently become possible to exercise, embed and conceal the power of such mechanisms of social control within the architectural design and spatial arrangement of commercialised spaces themselves (Allen 2006, 454). This has led shopping centres to become highly disciplined and digitalised power-spaces, replicating the structure and logic of the panopticon by inducing in the prisoner, or shopper, 'a state of 
conscious and permanent visibility that assures the automatic functioning of power' (Foucault 1995, 201). Here, sociological research into modern retail developments, such as Bristol's Cabot Circus (Flint 2002; Phillips 2010), has drawn on Bauman (2000) in order to propose that modern shopping centres can therefore be conceptualised as temples of postmodern consumption. They successfully operate as spectacles that induce visitors from far and wide to consume, by manufacturing a highly artificial environment that reassures those who visit that they are surrounded only by those 'lured by the same attractions' and 'guided by the same motives' (Bauman 2000, 100).

\section{Quasi-public spaces}

Modern shopping centres may appear to offer an unrestricted and inclusive space for all members of the community to enjoy. However, some critics have refuted such suggestions, instead proposing that this is merely a superficial façade or strategic attempt to gain legitimacy (Phillips 2010), in that these ultimately highly privatised shopping spaces are often only achieved through the destruction of formerly fully public places (Koskela 2000). If they are not totally destroyed, such public spaces are fundamentally transformed, in that they often become 'more intensely surveilled; more meticulously managed; more explicitly experiential, cosmopolitan, commercial, and commodified' (Madden 2010, 187). Here, Madden's research has directed attention towards the resulting lived experience of these newly configured urban spaces, advocating that they come to exemplify 'publicity without democracy' (2010, 213), offering a seemingly open environment that is, in reality, deeply immersed in, rather than totally detached from, the wider social divides and 'larger spatial politics within which it is located' (Madden 2010, 191).

Consequently, whilst such shopping centres may be experienced as open and accessible public spaces, it has been suggested that this 'illusion of a harmonious world' (Kohn 2001, 76) is a privilege that is afforded only to a very carefully defined socio-economic 'community' who are favoured due to their apparent ability to consume and thus conform to the particular and selective rules that govern behaviour within these spaces (Phillips 2010, 260; Stillerman and Salcedo 2012, 312). Therefore, whilst an aesthetically appealing world provides a constant though distorted distraction for the eye of the valued customer, it is those deemed to be the illegitimate users, 'flawed consumers' or undesirable 'objects out of place' (McCahill 1998; Davis 1990; White 2001 in Flint 2002, 54) who come to experience the harsh exclusionary realities of this law enforcement and spatial control, in both its explicit and more implicit forms (Layard 2010; Allen 2006). As a result of this, scholars often conclude that, rather than encouraging the development of truly open and accessible public spaces (Koskela 2000), shopping centres in fact pose a wider threat to the spontaneity of the surrounding cities and public spaces by continuing to limit freedoms (Stillerman and Salcedo 2012) and impose intentionally selective 'definitions of acceptable behaviour' (Flint 2002, 55). The construction and operation of shopping centres not only serves effectively to displace local social problems and further entrench social divisions (Madden 2010; Clement 2007), but it also heightens feelings of distrust and thus ultimately increases the possible risk of social conflict (Koskela 2000). This harsh reality is, however, largely concealed and made invisible to the eye of the visiting tourist or valued consumer, who rarely become immersed in the historical and contemporary realities of the surrounding city centres that remain outside of the walls safeguarding these temples of consumption (Bauman 2000). A case in point is the Cabot Circus shopping centre, located close to Bristol's existing inner-city shopping district.

\section{Bristol: The Circus comes to town}

Bristol is a large city in the South West of England whose prosperity is deeply rooted in the history of the slave trade. Bristol's city centre today includes a sprawling pedestrianised shopping district, comprised of national and international high street brands, express supermarkets and fast food establishments. At the turn of the century, Bristol's City Council ran a competition to 'determine which private developer would be given the contract to redevelop... [this] city centre', with two London firms, Land Securities 
'Bristol Alliance' (Layard 2010, 417). After plans were approved, Bristol Alliance's $£ 500$ million 'privately financed re-development scheme' (Phillips 2010, 262) soon got under away, and groundwork began on the construction of Bristol's latest shopping destination. Located next to the existing Broadmead shopping district, and opening to visitors on September 25, 2008, Cabot Circus was the final product of this multimillion-pound redevelopment scheme. Encompassing over 100 stores and restaurants, a cinema, a hotel, offices, accommodation and a carpark within its 36 acres (BBC Bristol 2008), Cabot Circus was said to offer a 'solution' 'based on principles of open architecture' to a perceived crisis of the city centre (Phillips 2010, 278).

Such an architectural 'solution' was not, however, achieved without much local resistance. Initially due to be named Merchants' Quarter, the developers faced significant backlash from local opponents who campaigned that such a name would glorify 'connotations with the city's slave trading past' (BBC News 2007). Despite the Bristol Alliance later opting to change the name, adding the 'Circus' suffix to reflect how the shopping centre would offer an exciting destination within the city, much like how 'a circus is a pivotal place where people gather' (BBC News 2007), objections to the socially and geographically exclusionary nature of the proposed design had already begun mounting (Clement 2007). Even during the initial design phase, concerns were raised that the relatively impoverished local communities had not been properly consulted, resulting in a proposed shopping centre that would ultimately only serve as a destination for visitors and the wealthy, whilst 'literally turn [ing]... its back upon St Paul's and St Jude's', which would soon 'become new road conduits and car park overspills' (Clement 2007, 104).

Moreover, it was also feared that Cabot Circus would come to inflict damage upon other neighbouring areas, in that whilst it may be located 'in the city centre, it will not be part of it' (Phillips 2010, 278). Therefore, local scholars argued that, rather than contributing to the diversity of the city and its public spaces, the introduction of Cabot Circus would instead ultimately serve to encroach upon and divide these former public domains (Clement 2007), specifically disrupting the 'meaning and function of Quakers Friars, Broadmead, Nelson Street and Castle Park by both appropriating and excluding them' (Phillips 2010, 278). Having been deemed unsafe, unattractive and rundown spaces (Tallon 2007 in Phillips 2010), the immediate environments of Broadmead, much of which was redeveloped following World War II bombing, and Quakers Friars, a largely concealed yet deeply historical and protected site (Layard 2010), were considered to be most at risk. The future was deemed to be especially bleak for Broadmead, whose ability to 'retain some connection to the "real' experience of city life as messy and disorganised' (Phillips 2010, 278) was very much threatened by future Cabot Circus expansion. Broadmead was ultimately destined to become redefined as a wasteland of very little significance, finding itself gradually reduced to a perimeter that would exist only to house those deemed unworthy of enjoying the new affluent shopping centre (Bauman 2000).

Since this time, however, there has been a lack of research into Cabot Circus and Broadmead that has investigated these claims empirically, with a notable absence of ethnographic research into the lived experiences of these reconfigured commercialised spaces. This research project seeks to address this gap, forming the fieldwork aspect of an undergraduate sociology unit that required students to conduct ethnographic research over a period of five weeks in an urban environment in Bristol. Having selected Bristol's inner-city shopping district as my desired setting, I approached the fieldsite with an interest in the privatisation of public space and the following key research questions: How do the structural designs and intended purposes of Cabot Circus and Broadmead differ? What is the link between architecture, ownership and surveillance in these commercialised spaces? In what ways has the existing development of Cabot Circus affected how Broadmead is defined, used and experienced? 


\section{Methods}

In order to address my key research questions, I developed and adopted a digital methodological approach. In response to the initial difficulties that I faced upon arriving at my fieldsite, I came to reconsider the basis of my participation and question ethnographic conventions, alternatively using my mobile phone and other digital technologies as a way to observe yet remain concealed within the distinctively impersonal and subtly regulated environment of the modern shopping centre.

\section{Using digital methods to capture a digital space}

Upon arriving at Cabot Circus for the first time in the capacity of a social researcher, I sat with a small red notebook in a restaurant on the top floor overlooking the shopping centre. It immediately became apparent that this was not somewhere to loiter or seek interaction, as people 'do not flock to these temples in order to talk and sociate' (Bauman 2000, 98). I watched attentively as customers clutched their phones in their hands and quickly made their way from one store to the next, whilst centre staff overlooked this movement, occupying themselves and listening attentively to their earpieces. Consequently, after paying the bill, I found myself attempting to mimic the behaviour of customers, establishing a repeated cycle of observing from one location for a short period before moving elsewhere to pause and 'jot notes at inconspicuous moments' (Fielding 2008, 274).

However, becoming increasingly aware of the central importance of digital technologies in Cabot Circus as I navigated my way around its various walkways, I soon found myself attempting to use digital methods of my own to capture and document the relationship between structure and surveillance within the field. Initially, this only involved using my phone as a digital notebook. However, recognising suggestions that 'the inclusion of audio or visual material... has been little more than 'eye candy' or 'background listening' to the ethnographic text' (Back 2012, 27), using my mobile phone gradually provided an innovative opportunity to use photographs to complement my own fieldnotes and illustrate my findings. By the time that I had spent ten hours at the fieldsite, my small red notebook was put away and my mobile phone was firmly clasped in my hand, serving as a medium that enabled me to document, capture and move easily between Cabot Circus and Broadmead. Approaching Broadmead with a similar research design, I collated, analysed and reflected on my digital fieldnotes and photographs throughout the fieldwork period, identifying key differences between the two commercialised spaces and any possible commonalities with existing sociological literature on shopping centres and malls. Contradictions between the written commentary on the intended design of Cabot Circus and the empirical reality of the shopping centre today formed the basis of the thematic analysis, with short repeated visits to the fieldsite providing valuable opportunities to observe evidence to support or refute emerging analytical hypotheses.

Whilst digital methods perhaps offer a largely discreet method by which to bridge the alleged gap between the presentation of culture through ethnographic writing and the 'fieldwork on which it is based (how culture is known)' (Marcus 1980 in Van Maanen 2011, 4), the use of digital methods was not totally unproblematic. Given ethical concerns that "[a] nonymity can also be compromised by the use of photographs' (BSA 2017, 6), I made an active and conscious effort to focus on capturing the architecture and surroundings of both Cabot Circus and Broadmead, rather than the people present or occupying the commercialised spaces. On a more practical level, the use of digital methods also meant that I was largely bound by the battery life of my mobile phone, whilst also feeling at a constant risk of becoming distracted by incoming messages and so missing potentially significant observations. Not only this, but my concern with the use of subtle surveillance methods within the environment of the contemporary shopping centre also led a heightened self-awareness of my role and position within Cabot Circus, leading me to spend a greater proportion of my time in Broadmead, where I felt able to stop and use my mobile phone without judgement. When I was conducting research in Cabot Circus, I feared that using my mobile phone within the fieldsite boundaries could be 
perceived as an unwelcome surveillance method that may become regulated or attract unwanted attention. This, for example, made it particularly time consuming to take good quality photographs, on one occasion resulting in somebody wrongfully presuming that I was loitering and looking puzzled at my phone because I was lost and in need of directions. Experiences such as this served only to further discourage me from approaching visitors or attempting to engage with staff members who might have been able to offer potentially valuable contributions to my research project.

\section{Becoming an active participant}

As a result of this heightened self-awareness, I came also to realise the central importance 'of the positioning, visibility and performance of [my]... own embodied self' (Coffey 1999, 59) as a social researcher. My attempts to simultaneously monitor and mirror the behaviour of other visitors, who may have paused but rarely loitered, and glanced but never stared, resulted in my digital fieldnotes coming to increasingly document the ways in which I felt a pressure to somehow straddle the roles of both observer and active 'participating body' (Coffey 1999, 70) in order alleviate my own awkwardness. However, on reflection, this was perhaps not simply a feeling that materialised from my initial engagements with the fieldsite, but was instead an underlying preconception that I had already constructed when I decided to invite friends to accompany me to a restaurant in Cabot Circus. Moreover, whilst I felt comfortable loitering for extended periods in Broadmead, upon returning to Cabot Circus, I often came to rely on the consumption of food as a way to facilitate and rationalise my need to remain stationary in an area characterised by constant movement. This enabled me to feel as if I was blending in with the people surrounding me, and thus attracting less attention. As a result, these reflexive attempts to mirror the behaviour of others, or to conform to the underlying expectation that one visits Cabot Circus solely for the purposes of consumption, became an ongoing participation strategy that I utilised with relative ease throughout my research, resulting in my digital fieldnotes becoming increasingly 'scattered with implicit and explicit references to the body' (Coffey 1999, 59).
Remaining an invisible ethnographer

This ease of participation could perhaps reflect my familiarity with this particular urban fieldsite, in that unlike many other ethnographers undertaking research, I was not required to turn my hand to previously untried tasks (Okely 2012) or to build relationships in order to gain access (Perez-Y-Perez and Stanley 2011). Moreover, this ease of access and familiarity with the fieldsite also highlighted the ways in which I, as an undergraduate university student, am also 'immersed in other communities' (Crang and Cook 2007, 38) outside of the field that afford me certain statuses and privileges. As a result of this, although I felt I was actively participating, I was perhaps only partially participating, simply experiencing and replicating the dominant and largely familiar lifeworld of the consumer (Okely 2012), whilst also using digital technologies as a strategy to position myself as both 'part of the researched group and simultaneously distanced from it' (Colic-Peisker 2004, 93). However, in another sense, the extent to which it was even necessary to be visible or active in order to experience a digitally commercialised and 'totally constructed visual experience' (Mirzoeff 1998 in Rose 2012, 4) such as Cabot Circus could be brought into question. Given that I was, for example, able to digitally experience and capture the Cabot Circus Christmas lights switch on event by watching an online livestream without needing to be physically present in person, it is possible that no amount of visible, active or sustained human participation would have enabled me to fully experience these digitally mediated aspects of Cabot Circus. Instead, the impersonal nature, design, location and intended purpose of my fieldsite meant that I was ultimately bound to adopt the role of a mere observer or silent ethnographer, lost in a crowd of distracted consumers.

\section{Cabot Circus}

Through strategic architectural design, Cabot Circus initially appears to offer visitors an open and publicly accessible shopping centre. However, closer examination reveals that it is a highly privatised, mediated and digital space in which power, regulation and surveillance have been carefully concealed. 


\section{Strategic design and architecture}

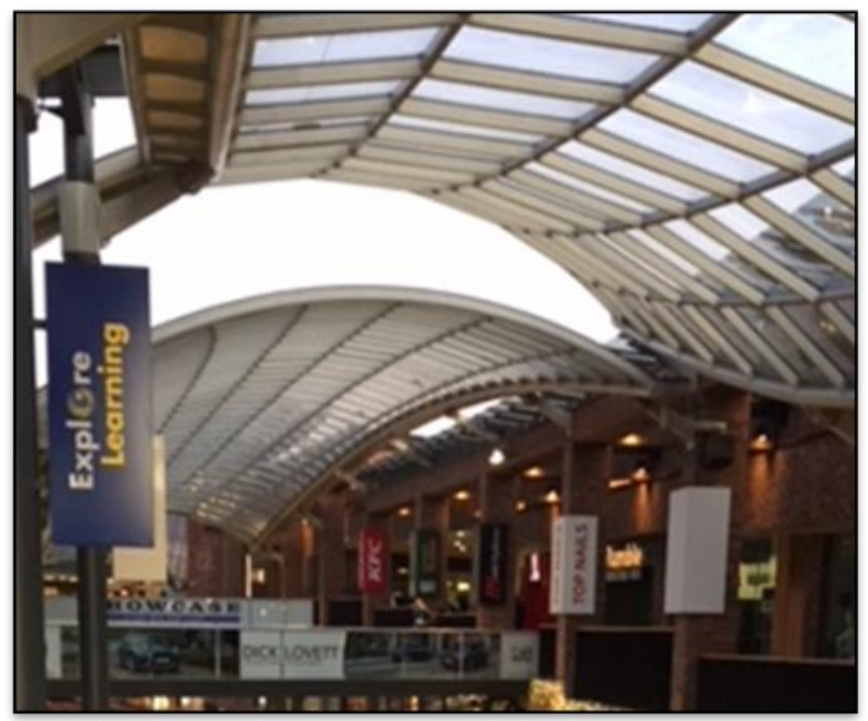

Figure 1: Cabot Circus roof [Photo by author]

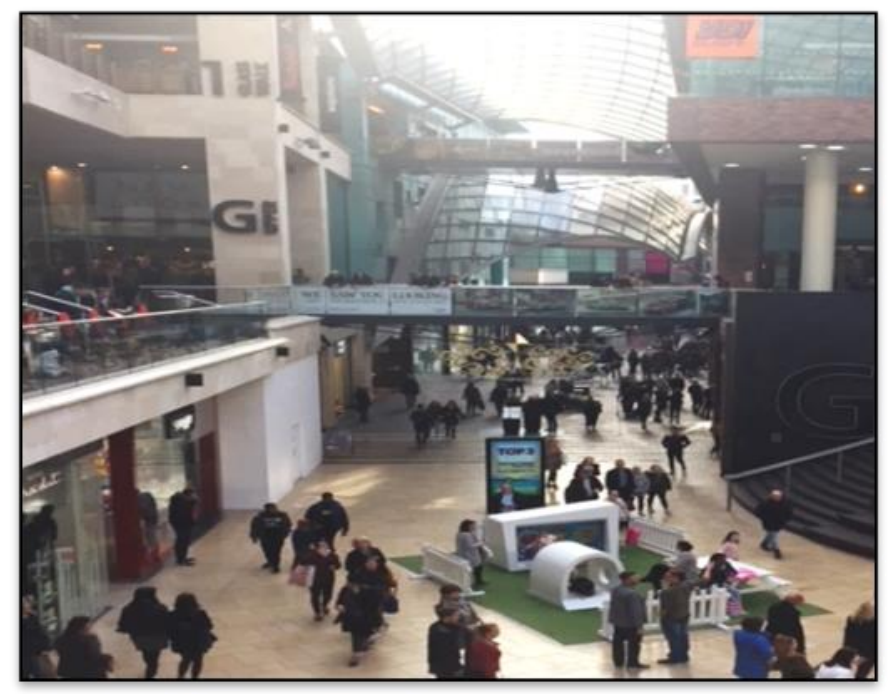

Figure 2: Cabot Circus shop floors and walkways

As argued by Allen (2006, 443), it is now possible to control and 'stage the public character of privatised spaces,' and indeed, through its architectural design, Cabot Circus is visually presented as an open space. There are no entrance doors or barriers that one must pass in order to enter, simply metal bollards marking out where no vehicles are permitted. The city air ventilates the shopping centre, whilst the uniquely suspended floating glass roof exposes the skies overhead (see figure 1), creating 'a series of interlocking and floating forms that choreograph the streets and buildings' (Phillips 2010, 278). The intermittent sounds of sirens echo throughout the shopping centre, but the sources are often difficult to identify, creating a feeling of disorientation. It is as if you are 'elsewhere' (Bauman 2000, 98), yet still surrounded by a moving city that you can sense but no longer visualise. Within the shopping centre, escalators and open glass walkways on each floor facilitate constant visitor flow (see figure 2), with visitors navigating familiar and predictable paths, moving as if they are 'responding to the invitations and suggestions inscribed in the design and layout' (Allen 2006, 452). Reinforcing Coffey's $(1999,75)$ suggestion that ethnographic research involves 'observing, interpreting and analysing the bodies and body perspectives of others' it was particularly noticeable that any closure of these regulated paths, even if only temporarily, created notable disruption within the shopping centre, forcing visitors to use their initiative and attempt to navigate their own pathways. These walkways also house the shopping centre's intentionally unconventional and uncomfortable seating arrangements, designed and positioned strategically in order to discourage loitering and so facilitate the constant visibility and surveillance of customers as they make only short and regulated pauses during their movement around the floors below (Foucault 1995, 187).

\section{Impersonal and artificial space}

As one walks around the shopping centre, it is very easy to fail to notice that one is in fact passing between different streets, which are given supposedly distinctive, meaningful and authentic personalities such as 'George White Street' and 'Brigstowe Street' (names which do not seem to predate the shopping centre, though they may reference points of local historical significance). This is because the overall brand image of Cabot Circus is highly commercialised, with only a few concealed signs of locality to 'remind... shoppers that they actually are in Bristol' (Minton 2012, xv). In contrast, capitalist markers of consumption are given centre stage in what becomes a distinctively 'postmodern spatial performance' (Shields 1992, 7), taking place within a highly artificial environment. Of crucial importance to this performative space is the central area on the ground floor (see figure 3) which, from early November, showcases an 
screen attached to its front, whilst also using visual and audio displays to promote seductive and tempting products, ranging from confectionary to sports cars (Bauman 2000). Overshadowing this is a large LED advertisement screen affixed to the side of the shopping centre lifts that rotates through a silent catalogue of various brands located within Cabot Circus, successfully captivating and arguably regulating the eyes of the consumer by manufacturing a highly individualised (Bauman 2000, 97) environment, where people learn to 'not look at each other but make themselves busy' (du Gay 2004 in Cochoy 2007, 115). One advert even cleverly plays on this logic, using 'we saw you looking' as a satirical strapline to perplex viewers, whilst perhaps also subconsciously reminding them to remain fixated on the immediate commercial distractions available directly in front of them.

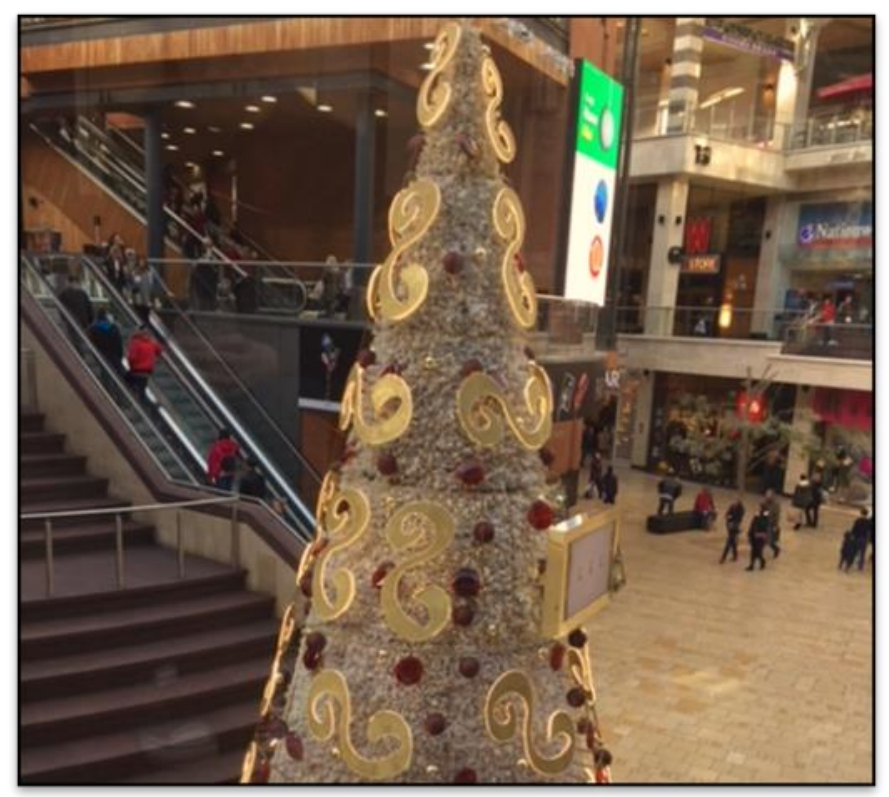

Figure 3: Central area on the Cabot Circus ground floor. Foreground: Christmas tree. Background: Advertisement board [Photo by author]

Whilst this central area provides a constant focal point within the commercialised space, at the time of my fieldwork Cabot Circus was elsewhere undergoing a phase of change and rebranding throughout all publicly accessible areas of the shopping centre. The largely outdated information podiums were being replaced with new sleek metallic illuminated store directories (see figure 4). These store directories would arrive tightly secured in bubble wrap, before being quickly hidden away using blacked out metal fencing. Suggesting that visitors should come to expect a certain appearance when visiting the shopping centre, whilst also reinforcing a very particular conception of beauty, these temporary fences would then be branded with the Cabot Circus logo and slogan, alongside an apologetic message addressed to customers: 'So sorry we're not looking our best, we will be back and beautiful as soon as we can.'

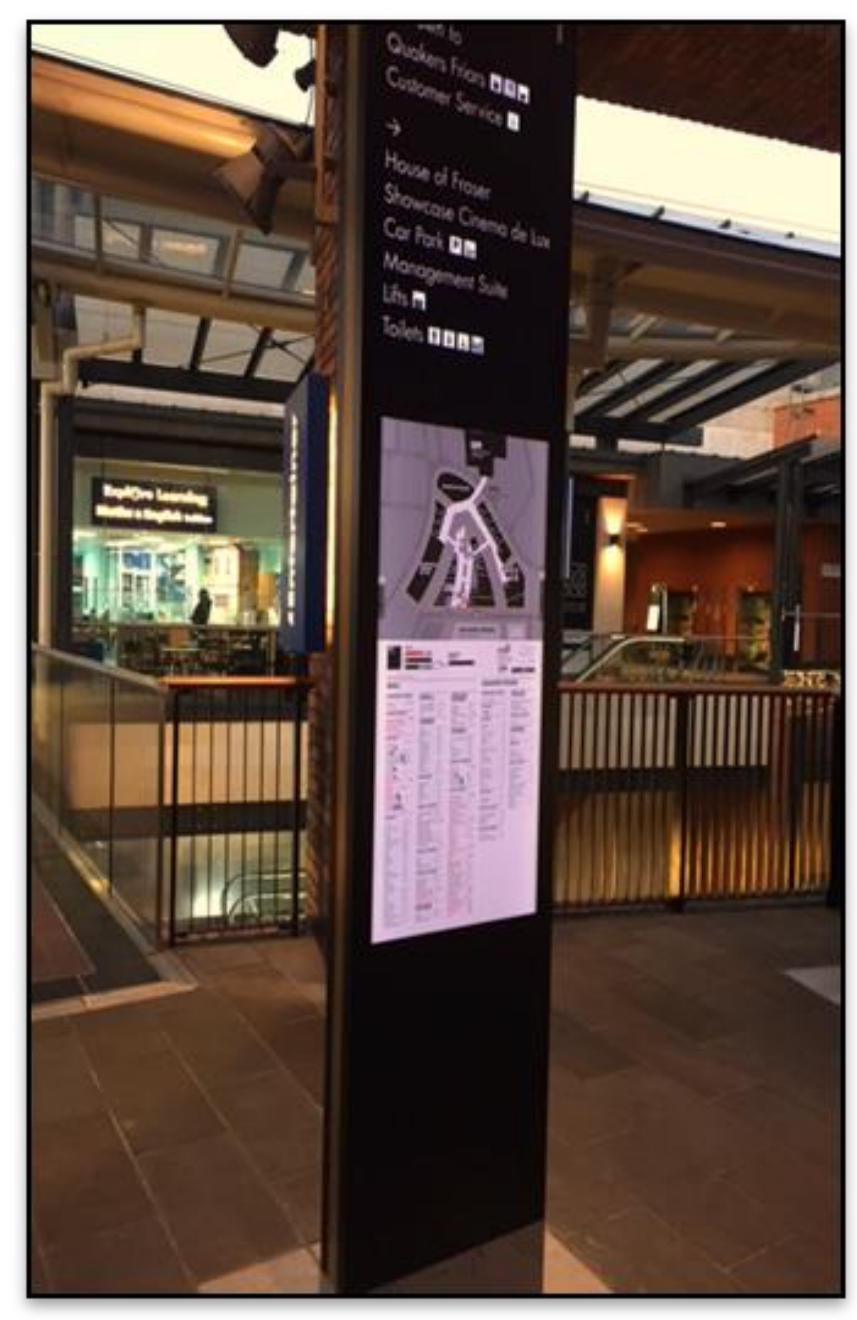

Figure 4: New store directory on the top floor of Cabot Circus [Photo by author]

By reducing the need for human interaction and directing the apologetic message directly to customers, this installation process appears to suggest not only that maintaining a certain appearance is a priority of upmost importance within Cabot Circus, but also that this appearance is maintained for a very specific demographic of possible consumers who come to be considered welcome, worthy and valued citizens in the shopping centre (Voyce 2006 in Layard 2010). Consequently, although Cabot Circus may initially appear to be an open and 
thus public space, I argue that in reality it 'is in fact carefully exclusive' (Marcuse 1997, 107), in that is very clear that 'nothing must stop, distract or harass visitors... from their original intention' of consumption (Cork 2017a). In order to further facilitate this, there are also signs located around the centre detailing how any behaviours perceived to pose a potential threat to these obedient shoppers are universally prohibited within the shopping centre (Layard 2010). Those behaviours listed include smoking, dog walking or cycling. Closer examination, however, reveals that these appear to be rules that are only symbolically displayed and selectively enforced.

\section{Symbolic control and performative}

\section{surveillance}

Despite being easily identifiable in their high visibility jackets, Cabot Circus' cleaning and security staff seem to perform a largely symbolic and performative role within the shopping centre. Rather than welcoming and interacting with visitors, security staff can often be found observing and overlooking the floors below from a stationary position on one of the shopping centre's glass walkways, or alternatively accompanying cleaning staff as they complete routine housekeeping tasks in a robotic manner, operating around the predictable movement of customers, but rarely engaging or communicating with them. Additionally, although one may witness others contravening the intended use of the shopping space, whether that be smoking, littering, walking a dog or riding a bicycle across the busy central area, such rule-breaking behaviour is very rarely countered by an active intervention made by the Cabot Circus staff themselves. The few exceptions to this rule witnessed during this fieldwork tended to involve youths, especially teenage boys, whose mere presence within Cabot Circus was often enough to warrant the attention and movement of security staff, who read it as potential to disrupt the rhythm of the shopping centre. The staff also appeared willing to approach individuals who sought to challenge such mechanisms of social control, using face-to-face confrontation as a precautionary measure to minimise possible disturbance of Cabot Circus' prevailing social order. However, unlike those behaviours explicitly prohibited on signage displayed around Cabot Circus, these situations tended to involve more indirect forms of deviant behaviour, with loud, loitering or seemingly unruly large groups of teenagers the most likely demographic to find themselves in confrontation with Cabot Circus' security staff.

This selective rule enforcement reflects the way in which Cabot Circus attempts, and largely succeeds, in exercising its invisible disciplinary power (Foucault 1995, 187) in order to encourage the self-regulation of behaviour through the constant use of more discreet surveillance methods that are embedded in the 'ambient qualities of the space' (Allen 2006, 441). Staff, for example, are guided to deal only with select individuals and groups through a visible radio and earpiece, whilst their own behaviour is also tracked through internal surveillance systems. Similarly, visitors to the shopping centre are periodically reminded that 'Cabot Circus is a no smoking area' through echoed overhead announcements, whilst remaining largely unaware that their personal mobile phones and every movements are in fact being tracked (Cork 2017a). This surveillance-based approach results in a shopping centre where the experience of the commercialised space itself becomes an 'expression of power' (Allen 2006, 441).

\section{Broadmead}

This experience quickly begins to change as one exits Cabot Circus and is immediately greeted by the noise and diversity of the neighbouring Broadmead shopping district (see figure 5). However, whilst remaining publicly accessible, the arrival of the Christmas market noticeably disrupts these realities of city life, resulting in Broadmead becoming a complex commercialised space characterised by a competition for ownership, authority and control.

\section{The realities of city life}

Unlike Cabot Circus, it is here in the seemingly unregulated outdoors that one may witness 'people, perhaps with alcohol issues, shouting from benches' or 'people with moral sensitivity issues shouting with special preaching books in their hands' (Cork 2017b). Not only this, but a walk through Broadmead is rarely without interaction, whether this be initiated by street 
performers playing their musical instruments, arts and craft stalls selling their wares, or apparently homeless people who line the walkways right up to the entrances of Cabot Circus. Therefore, unlike the artificially constructed demographic of Cabot Circus, Broadmead could be said to represent the messy and plural realities of Bristol's inner-city life, encompassing many differing individuals and unregulated behaviours, and thus largely operating as 'a space in which activity detrimental to consumption and with disruptive potential' can still erupt (Phillips 2010, 268).

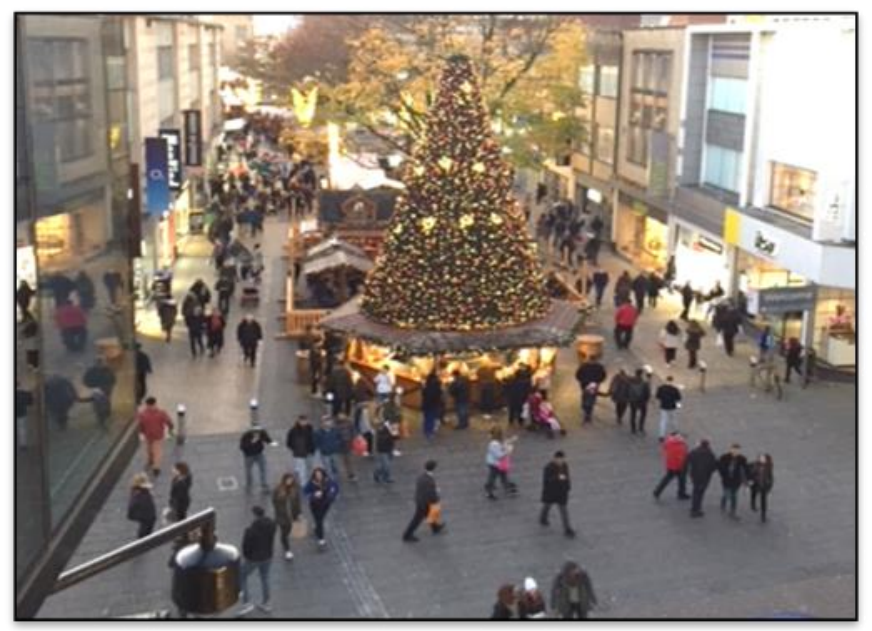

Figure 5: View of Broadmead and Christmas Market from Cabot Circus [Photo by author]

\section{Blurred boundaries between public and private}

However, although it is still officially public city centre land, this authentic feel of Broadmead quickly begins to change with the arrival of the Christmas market. This stretches the length of the pedestrianised shopping area, resulting in increased footfall, the displacement of street furnishings and an attempt to reinvent Broadmead as a visitor destination in its own right. Much like any city centre Christmas market, Bristol's comprises numerous wooden huts, each occupied by a different vendor selling Christmas gifts or serving traditional food, with the central circular area of Broadmead becoming an outdoor bar that serves alcohol until the early hours (see figure 5). However, unlike others, Bristol's Christmas market has recently become owned and operated by Cabot Circus, who have begun to establish a visible presence in Broadmead, which is therefore increasingly encroached upon by the rules, 'rhythm and tenor' (Bauman
2000, 98) of Cabot Circus. The many street performers, sellers and apparently homeless individuals, for example, find themselves forced to relocate, whilst consumption and those facilitating it, such as Cabot Circus security staff and market stall holders, are immediately given top priority. Here it appears that, despite attempts to separate and enclose its private and homogenised shopping centre from the messiness of Broadmead, the prioritisation of the maximisation of the profit motive has resulted in Cabot Circus ultimately colliding 'with the more heterogeneous and diverse public places outside' (Layard 2010, 429).

\section{Competition for authority}

This gradual intrusion of the surveillance strategies advocated by Cabot Circus security staff has led Broadmead to become a visually messy shopping environment, unclear in its identity, purpose, and boundaries. Whilst Cabot Circus may be characterised by a permanent state of stability and cleanliness, Broadmead appears to resist this. Similarly, whilst there may be rules that explicitly state who should be using Cabot Circus and for what purposes, this authority remains much more implicit and thus open to contestation in Broadmead. This confusion came to a head during fieldwork when Bristol City Council introduced externally employed enforcement officers to impose explicit rules and selective regulations upon Broadmead during the Christmas period. They issued fines to anyone that they saw committing 'environmental crimes, such as spitting or dropping litter, chewing gum or cigarette buts on the public street' (Bristol City Council 2017). When observing the behaviours of passers-by, these plain uniformed officers would often conceal themselves in shop doorways before stepping out into the public walkway and issuing a fine, seemingly using their authority to make a symbolic claim of ownership of this public space. In other cases, issuing such a fine may have been the result of the enforcement officers initially identifying a possible 'suspect' or 'victim' walking the streets of Broadmead, such as a person smoking or walking a dog without a lead, and then following them until their authoritative powers could be activated, for example, when a cigarette was dropped, or the dog became uncontrolled. 
However, unlike the largely symbolic and unchallenged ongoing surveillance employed by Cabot Circus security staff, the active, situational and noticeably disruptive policing strategy deployed by Bristol City Council's litter enforcement officers was met with many acts of resistance within Broadmead, with individuals attempting to continue to exercise their right to use this public space in whatever way they desire. For example, backlash emerged from angry members of the public and resentful Christmas market traders, who swiftly took to social media and local newspapers to argue that such 'intimidating behaviour' made 'passers-by feel uneasy', and thus hindered possible trade during the festive period (Smith 2017).

Beyond this, although there may have initially been some potential for the contrasting modes of regulation advocated by Cabot Circus' security staff and Broadmead's enforcement officers to co-exist, it became clear that Cabot Circus' security staff themselves were also keen to assert their dominance over Bristol's city centre. They maintained a visible presence at the invisible boundary lines separating Cabot Circus from Broadmead, whilst also exercising their right to inform Bristol City Council enforcement officers, whose surveillance strategies are yet to receive similar levels of technological and architectural support (Koskela 2000), that they do not 'have the authority to issue fines on private land' (Wood 2017). This struggle for primary ownership and control over Bristol's city centre suggests that, although urban planners may seek to design architecturally distinctive and spatially separated commercialised spaces, these will inevitably come to 'intersect with other worlds, with their boundaries neither fixed nor always clear to insiders or outsiders' (Pink et al. 2016, 102). However, whilst it may be clear that Broadmead's remaining lifespan as a publicly accessible commercialised space is relatively short, it remains to be seen whether Bristol City Council will, in the face of opposition, seek to continue to reap the financial rewards (in the form of fines) of its own rival surveillance efforts, or alternatively concede to the potentially larger and more lucrative commercial opportunities offered by supporting the Bristol Alliance to deliver their plans for a redeveloped Broadmead that formally extends the boundaries of Bristol's privatised commercial spaces.

\section{Conclusion}

From this comparative analysis of Cabot Circus and Broadmead during the festive season, it can ultimately be concluded that a combination of differing structural designs and architectures on the one hand, and a blurring of two formally opposed models of surveillance and ownership on the other, has resulted in two visually distinct yet increasingly overlapping commercialised spaces. Continual and largely discreet surveillance successfully operates in Cabot Circus, with power being 'represented not through its visibility but rather through its invisibility' (Foucault 1977 in Koskela 2000, 249). However, this is not the case in Broadmead, where recent attempts to introduce visible and privatised surveillance have been met with much resistance, with objectors claiming that it poses a threat to the openness and diversity of Bristol's public spaces. Given this, it appears that whilst the developers of Cabot Circus may have originally claimed to be preserving valuable yet underused spaces, it is now evident that this has ultimately only benefitted a select community of obedient and conforming shoppers who have the luxury of being able and invited to consume within this newly privatised space (Phillips 2010, 276).

Moreover, I suggest that it is ultimately due to its own attempts to "be both like and unlike a traditional high street and both enclosed and outside' (Phillips 2010, 278) that Cabot Circus has disrupted the complexities of Bristol's inner city and challenged the once democratised basis of public space (Madden 2010). It is also as a result of its developers' own expansion plans that Cabot Circus has found itself accused of attempting to conceal yet extend its ambient power (Allen 2006), by distorting neighbouring spaces into artificial yet seemingly authentic environments (Bauman 2000) where 'the surveillance and exclusion of particular individuals' becomes 'directly linked to facilitating the access of others' (Flint 2002, 64). This surveillance is facilitated by the disproportionate and architecturally enabled emphasis placed on the policing of 'the performance and management of the body' of 
those individuals or groups branded as external to the strategically redefined 'public' that are welcomed in the highly manufactured shopping environment (Madden, 2010). Those deemed to be undesirable are ultimately excluded due to their inability to regulate their behaviour and appropriately mirror the passive bodily movements of the conforming consumer (Coffey 1999, 59). When considered alongside Bristol City Council's litter enforcement officers' recent attempts to also define the boundaries of acceptable behaviour within the once seemingly disordered and uncontrollable Broadmead shopping district, I argue that the case study of Bristol's commercialised spaces illustrates how the once clear-cut divisions between public and private inner-city spaces have become increasingly blurred, with 'subtle, but no less insidious, registers of power... [now] increasingly part of the urban fabric' (Allen 2006, 454).

It is also worth reflecting on the influence that these surveillance methods had upon my role and subsequent behaviour in the field. By experiencing feelings of being both a powerful yet somewhat vulnerable researcher in a relatively familiar contemporary urban fieldsite, I was exposed to the ways in which the 'image of the heroic ethnographer confronting an alien culture is now untenable and fails to reflect much of what ethnographers do' (Coffey 1999, 22). By rejecting the traditional importance assigned to interviews 'as the prime technology for generating 'data" (Back 2012, 27) and alternatively recognising the plurality of possible ethnographic styles and representations, I sought to consider in this fieldwork how empirical and sociological knowledge can be developed through the use of observations, senses and 'a relatively artistic, improvised, and situated model of social research' (Rhys-Taylor 2013, 393). In addition to this, rather than allowing an absence of participants' voices to necessarily hinder my fieldwork, I was able to alternatively opt to make my own observations of the structure, power and internal voice of the shopping environment itself the central focus of my fieldwork. The largely anonymous nature of such commercialised spaces meant that a heightened awareness of my own internal feelings came to form the basis of my participation. To a degree, it may have appeared that I was simply uncomfortably loitering in a shopping centre, and this was in fact largely true. However, it was only through an ongoing reflexive awareness of my own positioning in this space (Berg and Lune 2014) that this feeling of uncomfortableness became something that I learnt to question and fundamentally reconsider.

\section{Acknowledgements}

I would like to thank Dr. Miriam Snellgrove for her feedback, guidance and support. 


\section{References}

Allen, J. 2006. 'Ambient Power: Berlin's Potsdamer Platz and the Seductive Logic of Public Spaces.' Urban Studies 43(2): 441-455.

Back, Les. 2012. 'Live Sociology: Social Research and its Futures.' The Sociological Review 60(S1):18-39.

Bauman, Zygmunt. 2000. Liquid Modernity. Cambridge: Polity Press.

BBC Bristol. 2008. 'Designing Cabot Circus,' 23 September. http:// www.bbc.co.uk/bristol/content/articles/2008/09/23/ cabot_architect_feature.shtml.

BBC News. 2007. 'New Shopping Centre Name Revealed,' 26 February. http://news.bbc.co.uk/1/hi/england/ bristol/6396919.stm.

Berg, Bruce, and Howard Lune. 2014. Qualitative Research Methods for the Social Sciences (eighth edition). Harlow: Pearson.

Bristol City Council. 2017. 'Clean Streets Enforcement Campaign.' https://www.bristol.gov.uk/bins-recycling/clean-streetsenforcement-campaign.

British Sociological Association (BSA). 2017. Statement of Ethical Practice. British Sociological Association. https:// www.britsoc.co.uk/media/24310/ bsa_statement_of_ethical_practice.pdf.

Clement, Matt. 2007. 'Bristol: 'Civilising' the Inner City.' Race \& Class 48(4):97-105.

Cochoy, Franck. 2007. 'A Sociology of Market-Things: On Tending the Garden of Choices in Mass Retailing.' The Sociological Review 55 (s2):109-129.

Coffey, Amanda. 1999. The Ethnographic Self: Fieldwork and the Representation of Identity. London: SAGE Publications.

Colic-Peisker, Val. 2004. 'Doing Ethnography in "One's Own Ethnic Community": The Experience of an Awkward Insider.' In Anthropologists in the Field: Cases in Participant Observation, edited by Lynne Hume and Jane Mulcock, 82-94. New York: Columbia University Press.

Cork, Tristan. 2017a. 'Ten Things You Probably Didn't Realise You Can't Do in Cabot Circus.' Bristol Post, 21 August. http:// www.bristolpost.co.uk/whats-on/shopping/cabot-circus-bristolshopping-rules-8399. 
Cork, Tristan. 2017b. 'Is Turning the Public Street Private a Price Worth Paying for Cabot Circus Expansion?' Bristol Post, 11 October. http://www.bristolpost.co.uk/news/news-opinion/ turning-public-street-private-price-607598.

Crang, Mike, and Ian Cook. 2007. Doing Ethnographies. London: SAGE Publications.

Fielding, Nigel. 2008. 'Ethnography.' In Researching Social Life (third edition), edited by Nigel Gilbert, 266-284. London: SAGE Publications.

Flint, John. 2002. 'Surveillance and Exclusion Practices in the Governance of Access to Shopping Centres on Periphery Estates in the UK.' Surveillance \& Society4(1/2):52-68.

Foucault, Michel. 1995. Discipline and Punish: The Birth of the Prison (second edition). Translated by Alan Sheridan. New York: Pantheon Books.

Kohn, Margaret. 2001. 'The Mauling of Public Space.' Dissent 48(2):71 -77 .

Koskela, Hille. 2000. “The Gaze Without Eyes': Video-Surveillance and the Changing Nature of Urban Space.' Progress in Human Geography 24(2):243-265.

Layard, Antonia. 2010. 'Shopping in the Public Realm: A Law of Place.' Journal of Law and Society 37(3):412-441.

Levy, Samantha, and Susannah Church. 2012. 'Opening Doors and Sitting on Floors: Public Events in Private Spaces: The (Re)Appropriation of Space Through Grassroots Events in Halifax.' The Journal for Undergraduate Ethnography 2(1):1-8.

Madden, David. 2010. 'Revising the End of Public Space: Assembling the Public in an Urban Park.' City and Community 9(2):187-207.

Marcuse, Peter. 1997. 'Walls of Fear and walls of support.' In Architecture of Fear, edited by Nan Ellin, 101-14. New York: Princeton Architectural Press.

Minton, Anna. 2012. Ground Control: Fear and Happiness in the Twenty-First-Century City(second edition). Penguin UK.

Okely, Judith. 2012. Anthropological Practice: Fieldwork and the Ethnographic Method. London: Berg. 
Perez-Y-Perez, Maria, and Tony Stanley. 2011. 'Ethnographic Intimacy: Thinking through the Ethics of Social Research in Sex Worlds.' Sociological Research Online 16(2). http:// www.socresonline.org.uk/16/2/13.html.

Phillips, Mary. 2010. 'From the Waste Land to Past-Present Fuchsia: The Re-Development of the Broadmead Shopping Centre.' Culture and Organization 16(3):259-282.

Pink, Sarah, Heather Horst, John Postill, Larissa Hjorth, Tania Lewis, and Jo Tacchi,. 2016. Digital Ethnography Principles and Practice. London: SAGE Publications.

Rhys-Taylor, Alex. 2013. 'The Essences of Multiculture: A Sensory Exploration of an Inner-City Street Market.' Identities: Global Studies in Culture and Power 20(4):393-406.

Rose, Gillian. 2012. 'Researching with Visual Materials: Towards a Brief Survey.' In Visual Methodologies: An Introduction to Researching with Visual Materials (third edition), edited by Gillian Rose, 1-18. London: SAGE Publications.

Shields, Rob. 1992. 'Spaces for the Subject of Consumption.' In Lifestyle Shopping: The Subject of Consumption, edited by Rob Shields, 1-20. London: Routledge.

Smith, Joseph. 2017. 'Bristol's Litter Police Are 'Backing People Into Corners and Shouting At Them' Claims Christmas Market Stallholder'. Bristol Post, 22 November. http:// www.bristolpost.co.uk/news/bristol-news/bristols-litter-policebacking-people-811811.

Stillerman, Joel, and Rodrigo Salcedo. 2012. 'Transposing the Urban to the Mall: Routes, Relationships, and Resistance in Two Santiago, Chile, Shopping Centers.' Journal of Contemporary Ethnography 41(3):309-336.

Van Maanen, John. 2011. Tales of the Field (second edition). Chicago: University of Chicago Press.

Wood, Alex. 2017. 'Bristol City Council Forgot to Tell Cabot Circus it was Sending in the "Litter Police". Bristol Post, 25 November. http://www.bristolpost.co.uk/news/bristol-news/bristol-citycouncil-forgot-tell-829633. 